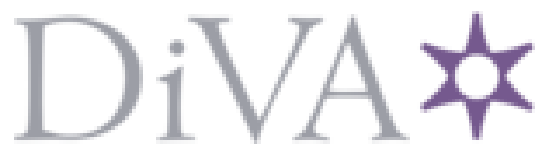

http://www.diva-portal.org

This is the published version of a paper published in Environmental Science and Technology.

Citation for the original published paper (version of record):

McCallum, E., Cerveny, D., Fick, J., Brodin, T. (2019)

Slow-Release Implants for Manipulating Contaminant Exposures in Aquatic Wildlife: A

New Tool for Field Ecotoxicology

Environmental Science and Technology, 53(14): 8282-8290

https://doi.org/10.1021/acs.est.9bo1975

Access to the published version may require subscription.

N.B. When citing this work, cite the original published paper.

Permanent link to this version:

http://urn.kb.se/resolve?urn=urn:nbn:se:umu:diva-161998 


\title{
Slow-Release Implants for Manipulating Contaminant Exposures in Aquatic Wildlife: A New Tool for Field Ecotoxicology
}

\author{
Erin S. McCallum, ${ }^{*},+₫ \odot$ Daniel Cerveny, ${ }^{\S, \|}$ Jerker Fick, ${ }^{\S}$ and Tomas Brodin ${ }^{\ddagger}$ \\ ${ }^{\dagger}$ Department of Ecology \& Environmental Science, Umeå University, SE-90187 Umeå, Sweden \\ ${ }^{\ddagger}$ Department of Wildlife, Fish, and Environmental Studies, Swedish University of Agricultural Sciences (SLU), SE-90183 Umeå, \\ Sweden \\ ${ }^{\S}$ Department of Chemistry, Umeå University, SE-90187 Umeå, Sweden \\ "Faculty of Fisheries and Protection of Waters, South Bohemian Research Center of Aquaculture and Biodiversity of Hydrocenoses, \\ Research Institute of Fish Culture and Hydrobiology, University of South Bohemia in Ceske Budejovice, Zátiší 728/II, 38925 \\ Vodňany, Czech Republic
}

\section{Supporting Information}

ABSTRACT: Field-based ecotoxicology studies are invaluable for uncovering the effects of contaminants of emerging concern (CECs) on aquatic organisms. However, large-scale exposures are still very rare due to prohibitive costs, the availability of replicated habitats, and the potential for exposure to cause lasting damage to the environment. Here, we evaluated the viability of internal slow-release implants as an alternative method for manipulating CEC exposures in aquatic wildlife using two fat-based carriers (coconut oil and vegetable shortening). We treated roach (Rutilus rutilus) with implants containing a high $(50 \mu \mathrm{g} / \mathrm{g})$, low $(25 \mu \mathrm{g} / \mathrm{g})$, or control $(0 \mu \mathrm{g} / \mathrm{g})$ concentration of the behavior-modifying pharmaceutical oxazepam. We then measured oxazepam

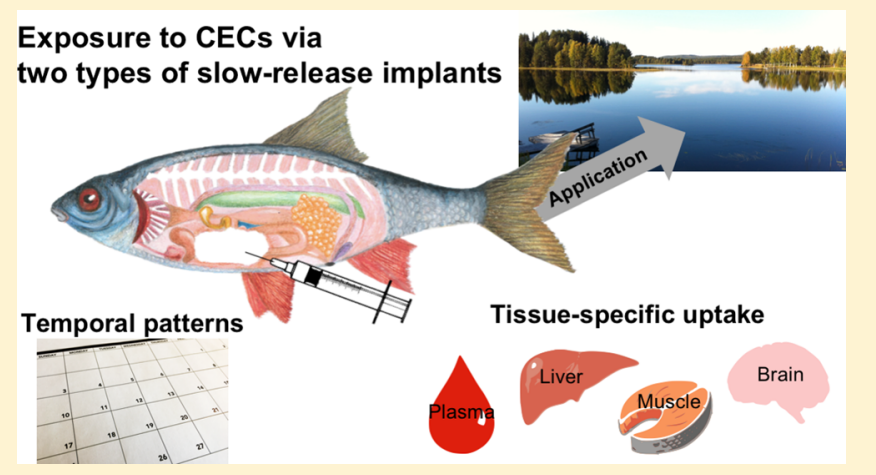
uptake in four tissues (plasma, muscle, liver, and the brain) over 1 month. The two carriers released oxazepam differently: coconut oil was the superior implant type because it delivered a more consistent dose across time, while vegetable shortening released oxazepam rapidly at the start of the exposure period. For both carriers and treatments, the brain and liver contained the most oxazepam. Overall, the method is a promising technique for controlled manipulations of pharmaceuticals in fish, and we have provided some of the first data on the suitability and contaminant release kinetics from different implant types.

\section{INTRODUCTION}

Recently, scientists have advocated for studies to "upscale" their approach to measuring the effects of chemicals of emerging concern (CECs) in the natural environment. ${ }^{1-4}$ CECs encompass a range of compounds (e.g., pharmaceuticals, pesticides, perfluorinated alkylated substances) that have diverse sources and fates in the environment (e.g., wastewater treatment plants, manufacturing, animal husbandry). ${ }^{5,6}$ Upscaling research on CECs broadly means increasing the study complexity to, for instance, include multiple species, incorporate natural environmental variability, or increase the temporal or spatial scale at which studies are being conducted. ${ }^{2,4}$ Environmental risk assessment for CECs relies on extrapolating effects measured in individual-level laboratory assays to population-level outcomes, even though these extrapolations sometimes fail to accurately capture the effects of CECs in the wild. ${ }^{78}$ Field-based, ecosystem-level, or wholelake exposure experiments are powerful tools for environmental scientists, ecologists, and toxicologists to study the effects of CECs in a way that dramatically increases the environmental relevance of their findings. These experiments yield valuable data on how CECs affect organisms across temporal scales, alter trophic interactions among species, impact survival, and ultimately determine population growth or decline. ${ }^{9,10}$ However, despite these compelling arguments of why field ecotoxicology is important, such studies are still extremely rare. Several reasons may underlie the reluctance to carry out such studies, such as limited access to replicate habitats of optimal size and structure, these studies are often prohibitively expensive, and the exposures may have longlasting effects that will limit the habitat's use for future studies. Here we test and suggest an exposure method for field ecotoxicology studies that will allow researchers to overcome these challenges to make exposure studies more feasible.

Received: April 2, 2019

Revised: $\quad$ May 7, 2019

Accepted: May 8, 2019

Published: May 8, 2019 
Internal slow-release implants are one viable method to manipulate CEC exposures in aquatic organisms for use in large-scale experiments. In brief, this method involves suspending a known concentration of a compound in a liquefied vegetable fat-based carrier (e.g., coconut oil, cocoa butter). This solution can then be injected into the intraperitoneal (IP) cavity, where it solidifies. Injectable implants have been used extensively in endocrinology research to uncover how steroid hormones (e.g., cortisol, estradiol) modulate fish physiology, behavior, and immune function. ${ }^{11,12}$ This technique has several clear benefits for large-scale ecotoxicology experiments. First, an internal implant reduces pollution caused by large-scale exposures, making the environment viable for reuse in future studies. Second, both control and exposed organisms can be studied in the same lake or habitat because the exposure is internal, eliminating the need for replicated experimental habitats. Finally, the implants are inexpensive and practical to prepare and administer in the laboratory or field. To date, injectable implants have been used in several laboratory-based studies focusing on CECs. ${ }^{13,14}$ However, there has been little to no research on the suitability of different implant types, the release kinetics of contaminants from the implants over time, or patterns of tissue-specific uptake in exposed organisms.

The objective of this study was to evaluate slow-release implants as a novel method for delivering an internal CEC exposure in aquatic organisms. Specifically, we measured how two different implants released a behavior-modifying pharmaceutical, the benzodiazepine oxazepam. Benzodiazepines are a class of highly prescribed anxiolytic medications ${ }^{15,16}$ that are widespread contaminants in treated wastewater effluents, surface waters, and are persistent in aquatic sediments. ${ }^{17-19}$ Benzodiazepines can modulate fish physiology and behavior important for fitness at relatively low concentrations $(\sim 1 \mu \mathrm{g} /$ $\mathrm{L}^{20-22}$ but see also ref 23 ). For example, fish exposed to benzodiazepines exhibit reduced stress, are more active, more bold or likely to take risks, and less social, and this has been found in multiple fish species..$^{20-22,24-26}$ We therefore selected a benzodiazepine (oxazepam) as our model compound because of the clear risk they pose to aquatic organisms. ${ }^{27}$ Benzodiazepines bioconcentrate in fish tissues, ${ }^{23,28}$ and their chemical and physical properties (e.g., $\log P$ ) are similar to other behavior-modifying compounds, making our findings widely applicable. ${ }^{29}$ To develop and validate our method, we compared the effectiveness of two fat-based carriers at releasing oxazepam. We measured the tissue-specific uptake of oxazepam from the implants across four tissues (liver, brain, muscle, plasma) over a month-long exposure period to establish the time frame over which the implants are effective. To the best of our knowledge, this is the first study to provide comprehensive data on the release kinetics and tissue-specific uptake for a pharmaceutical from slow-release implants in aquatic organisms.

\section{MATERIALS AND METHODS}

2.1. Fish Collection and Housing. We collected wild adult roach from Ume River near Umeå, Sweden, using umbrella traps and transported them live to Umeå University. Fish were housed in four aerated large, $1500 \mathrm{~L}$, nonchlorinated groundwater flow through tanks for the duration of the experiment. Fish were fed a mixture of floating and sinking pellets (BioMar Inicio) until satiation, once daily. All fish handling and experimental procedures were approved under animal ethics permit Dnr A-8-15 to T. Brodin.

2.2. Implant Preparation and Exposure. We prepared the implants by dissolving oxazepam (CAS 604-75-1, Merck) in one of two implant types, vegetable shortening (VS, Crisco, https://www.crisco.com/, a blend of soybean and palm oils) or coconut oil (CO, Kung's Markatta Virgin Coconut Oil, https://www.kungmarkatta.se/). These two substances were chosen because they remain pliable and soft at low temperatures characteristic of temperate freshwater environments, while other compounds (e.g., cocoa butter) harden and can create brittle implants with sharp edges. ${ }^{30-32}$ These two substances are also commercially available, easily acquired, and cost-effective. We used three exposure treatments, a high dose (50 $\mu \mathrm{g} / \mathrm{g}$ of implant), low dose $(25 \mu \mathrm{g} / \mathrm{g}$ of implant), or control dose $(0 \mu \mathrm{g} / \mathrm{g}$, only implant with no oxazepam $)$. Oxazepam was stirred in the liquefied carrier for $20 \mathrm{~min}$ and then sonicated in an ultrasound bath at $30{ }^{\circ} \mathrm{C}$ for $15 \mathrm{~min}$ (Babdelin Sonorex Digitec) to ensure it was thoroughly mixed.

To implant the fish, we first anesthetized them using MS222 (ethyl 3-aminobenzoate methanesulfonate; Merck; at $0.15 \mathrm{~g} /$ L) and measured body mass (Mettler Toledo, accurate to 0.01 g). We then inserted a passive integrated transponder (PIT) tag (12 mm, Biomark USA) to identify fish throughout the study by making a small $<5 \mathrm{~mm}$ incision on the left side of the fish's anterior surface just behind the ventral fin. We implanted the fish at a dose of $5 \mu \mathrm{L}$ of implant per g of body weight via intraperitoneal (IP) injection with a blunted 18-gauge needle using the same incision as for the PIT tag. We placed the fish's abdomen on ice for $\sim 30 \mathrm{~s}$ after injection to ensure the implant had solidified and then allowed them to recover in a separate aerated tank for $1 \mathrm{~h}$. We returned the fish to their housing tank after the procedure. An additional five fish were immediately sampled (overdose of MS222 $0.45 \mathrm{mg} / \mathrm{L}$ ) without receiving an implant or tag to serve as a baseline (different from control fish, see below).

We euthanized five fish per treatment after $24 \mathrm{~h}$ of exposure and every 3 days after that until 25 days had passed (i.e., $24 \mathrm{~h}$, day 4 , day 7 , day 10 , day 13 , day 16 , day 19 , day 22 , day 25 ). A smaller subset of fish were implanted as the control fish and were euthanized only after $24 \mathrm{~h}$, day 13 , and day 25 (corresponding to the start, middle, and end of the experiment). We collected plasma from all fish before terminal sampling on $24 \mathrm{~h}$, day 13 , and day 25 . All sampled fish were euthanized and frozen at $-18{ }^{\circ} \mathrm{C}$ for later chemical analyses. We monitored housing tank temperature $\left(8.4 \pm 0.42{ }^{\circ} \mathrm{C}\right.$; range, 7.8-9.5 ${ }^{\circ} \mathrm{C}$; YSI pro ODO), dissolved oxygen (13.01 \pm $0.23 \mathrm{mg} / \mathrm{L}$; range, $12.59-13.39 \mathrm{mg} / \mathrm{L}$; YSI ProODO), and $\mathrm{pH}$ (7.60 \pm 0.21 ; range, 7.27-7.97; Mettler Toledo bench $\mathrm{pH}$ reader) over the exposure period. During the study, three fish died from unknown causes (two from high $\mathrm{CO}$, one from low CO). See the Supporting Information Table S1 for sample sizes and average fish body size by treatment.

2.3. Sample Pretreatment and Chemical Analyses. After thawing, we weighed samples of muscle, liver, and brain tissue from each fish $(0.1 \pm 0.01 \mathrm{~g})$ in $2 \mathrm{~mL}$ polypropylene (PP) tubes. After adding $50 \mathrm{ng}$ of internal standard (Oxazepam-D5, CAS-ID 65854-78-6, Merck; $50 \mu \mathrm{L}$ of $1 \mu \mathrm{g}$ / $\mathrm{mL}$ in methanol), samples were extracted twice, sequentially using $1.5 \mathrm{~mL}$ of acetonitrile. Samples were homogenized for 4 min at 42000 oscillations per minute with zirconium beads (Mini Beadbeater, Biospec, Bartlesville, OK) and then centrifuged at $17500 \mathrm{~g}$ for $10 \mathrm{~min}$ (Beckman Coulter 
Microfuge 22R Centrifuge). This protocol was followed for both eluent mixtures individually, and the supernatants were combined, evaporated to dryness $(<20 \mu \mathrm{L})$, and reconstituted in $130 \mu \mathrm{L}$ of methanol. Final extracts were transferred into the glass autosampler vials with a $200 \mu \mathrm{L}$ insert and kept frozen at $-18{ }^{\circ} \mathrm{C}$ (for a minimum of $24 \mathrm{~h}$ ). Directly before analysis, the samples were centrifuged again to settle precipitated proteins and other solid particles in the sample.

We thawed and pretreated plasma samples $(50 \mu \mathrm{L})$ in $2 \mathrm{~mL}$ PP tubes by adding $50 \mathrm{ng}$ of the internal standard (OxazepamD5), $50 \mu \mathrm{L}$ of methanol, and $20 \mu \mathrm{L}$ of water (with $0.1 \%$ formic acid). Samples were mixed for 2 min (Mini Beadbeater, Biospec, Bartlesville, OK; no beads were used), frozen at -18 ${ }^{\circ} \mathrm{C}$ for $1 \mathrm{~h}$, then thawed and centrifuged at $17500 \mathrm{~g}$ for $10 \mathrm{~min}$. Final extracts were then transferred again into glass autosampler vials with $200 \mu \mathrm{L}$ inserts and analyzed.

We verified the amount of oxazepam in the implants from three randomly selected fish from each carrier and oxazepam treatment sampled on day 1, day 13, and day 25 (start, middle, and end of the experiment). We excised the implant from the body cavity, homogenized it, and sampled $0.1( \pm 0.01) \mathrm{g}$ for analysis. The implant was extracted following the same steps used in the tissue extractions, except that the centrifuge was set at $0{ }^{\circ} \mathrm{C}$ to solidify the fat from the liquid phase. We also confirmed that no oxazepam was present in the exposure water by analyzing a sample of water taken from each tank at the start and end of the experiment. Water samples were thawed and prepared by adding $5 \mathrm{ng}$ of internal standard (Oxazepam-D5) to $10 \mathrm{~mL}$ of water. Water samples were acidified with $5 \mu \mathrm{L}$ of formic acid and analyzed.

2.4. Instrumental Analysis. All biota samples were analyzed using a method of liquid chromatography-tandem mass spectrometry (LC-MS/MS). An ultrahigh-pressure liquid chromatography (UHPLC) system equipped with an Ultimate 3000 pump (LPG-3400SD, Thermo Fisher Scientific, San Jose, CA) and a PAL HTC autosampler (CTC Analytics AG, Zwingen, Switzerland) connected to the Hypersil GOLD column $(2.1 \mathrm{~mm} \times 50 \mathrm{~mm}, 3 \mu \mathrm{m}$, Thermo Fisher Scientific) was used for separation of the target analytes. A TSQ Quantiva triple quadrupole mass spectrometer (Thermo Scientific) equipped with a heated-electrospray ionization (HESI) ion source operating in positive mode was used for analyte identifications and determinations. More information about MS/MS including the transition ions and HESI settings is given in the Supporting Information (Table S2). A detailed description of the method and instrumentation is given in our previous work. $^{26}$

Our analytical method for fish samples was validated regarding its linearity, repeatability, limit of quantification (LOQ), and recovery. The method was linear over the range of 1 to $50 \mathrm{ng} / \mathrm{g}\left(R^{2}=0.998\right)$. The repeatability of our method was tested for 15 replicates across all tissues; the relative standard deviation (RSD) of replicates was $11 \%$. The recovery of oxazepam was studied by spiking tissues $(N=4$ of each) originating from the control fish with $10 \mathrm{ng}$ of oxazepam per sample before the extraction procedure. The average recovery ranged from 106 to $108 \%$ depending on the fish tissue. The instrumental LOQ was derived from the calibration curve. The peak area corresponding to this LOQ was then used for calculation of LOQs in the individual samples. Corresponding values reflect differences among the internal standard (IS) recovery, weight, and final volumes of the extract in each sample. The mean LOQs were in range from 0.5 to $1.5 \mathrm{ng} / \mathrm{g}$ depending on the tissue/plasma. More detailed information about recoveries and LOQs is given in the Supporting Information (Table S3). Several blank samples were measured with each series of samples, and in none of those was oxazepam found above the LOQ.

All implant and water samples were analyzed using a method of LC-MS/MS, a system with a triple-stage quadrupole mass spectrometer (Quantum Ultra EMR, Thermo Fisher Scientific, San Jose, CA) coupled with a liquid chromatographic pump (Accela, Thermo Fisher Scientific) and an autosampler (PAL HTC, CTC Analytics AG, Zwingen, Switzerland). Heated electrospray (HESI), krypton $10.6 \mathrm{eV}$, in positive ion mode was used for ionization of the pharmaceuticals. Specific details related to the determination have been described in detail previously. ${ }^{33}$ Our analytical method for water samples have been validated regarding its linearity, repeatability, limit of quantification (LOQ), and recovery. The extraction method used for the implants was validated in this study, and the standard curve was shown to be in the linear range between 5 and $250 \mathrm{ng} / \mathrm{g}\left(R^{2}=0.999\right)$. Repeatability of our method was tested $(N=10)$, and the RSD of replicates was $6 \%$. The recovery of oxazepam was studied in both vegetable shortening and coconut oil by spiking both with oxazepam $(N=6$ each, $100 \mathrm{ng} / \mathrm{g}$ ) before the extraction procedure. Average recovery was $79 \%(21 \%$ RSD) in coconut oil and 61\% (RSD 19\%) in vegetable shortening. Instrumental LOQ was derived from the calibration curve. The peak area corresponding to this LOQ was then used for calculation of LOQs in individual samples. The LOQ was $5 \mathrm{ng} / \mathrm{g}$ in the implant samples. Several blank samples were measured with each series of samples, and no oxazepam was detected above the LOQ in any of these samples.

2.5. Statistical Analyses. All statistical analyses were conducted in $R$, version 3.5.2. ${ }^{34}$ We used a linear mixed effects model (LMM, lme4 package ${ }^{35}$ ) to test if the concentration of oxazepam in tissue varied with sampling date (continuous factor), implant carrier (categorical factor), treatment (categorical factor), and tissue type (categorical factor). We included a random effect of fish ID to account for repeated samples taken from the same fish. We explored all interaction effects in the model and removed them when nonsignificant. Oxazepam concentrations were log-transformed to meet model assumptions. To identify differences in uptake among tissues, we followed our analyses with a Tukey posthoc to test for differences among slopes or group means (emmeans pack$\left.\operatorname{age}^{36}\right)$.

To determine if tissue oxazepam concentrations were proportional to the implant treatment (i.e., high vs low), we calculated an implant bioconcentration factor (implant-BCF, IBCF) for oxazepam uptake in tissues from the implants using the following equation:

$$
\text { implant-BCF }=\frac{\text { tissue concentration }}{\text { nominal implant concentration }}
$$

where the concentration in tissues and implants was in $\mathrm{ng} / \mathrm{g}$ (or $\mathrm{ng} / \mathrm{mL}$ for plasma). We then ran a LMM on IBCF using the same fixed and random factors listed above. We evaluated the intrafish variability of oxazepam concentration among tissues by plotting correlations and extracting Pearson correlation coefficients. To compare tissue-uptake between implants and waterborne oxazepam exposures, we collected and plotted average exposure water and tissue concentrations from already published studies (see full list, supplementary 
A

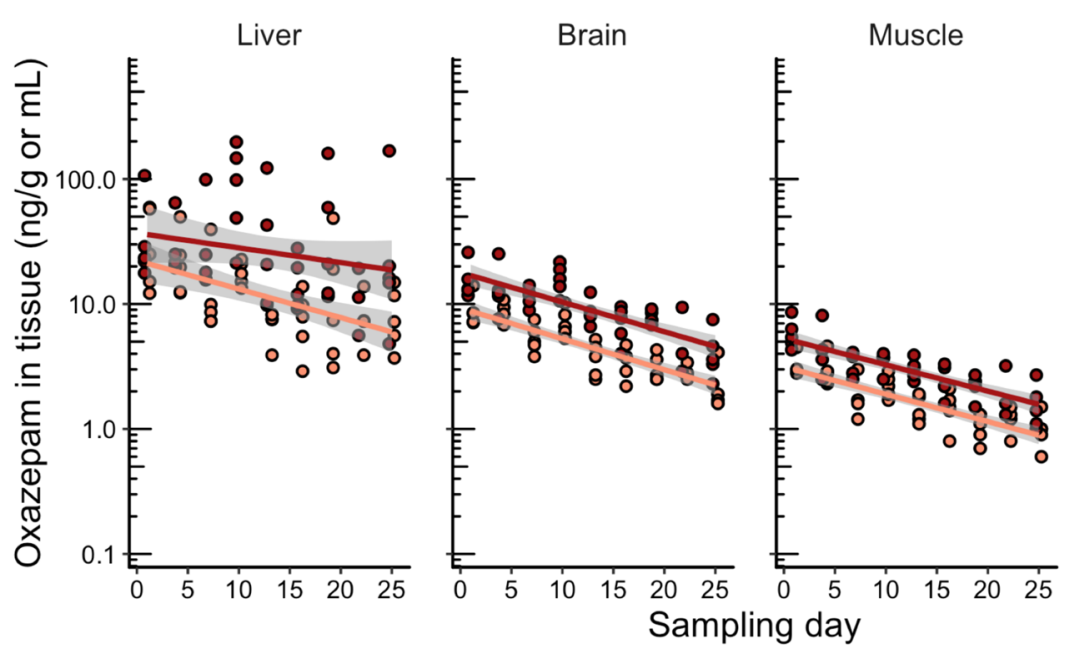

Coconut oil

B

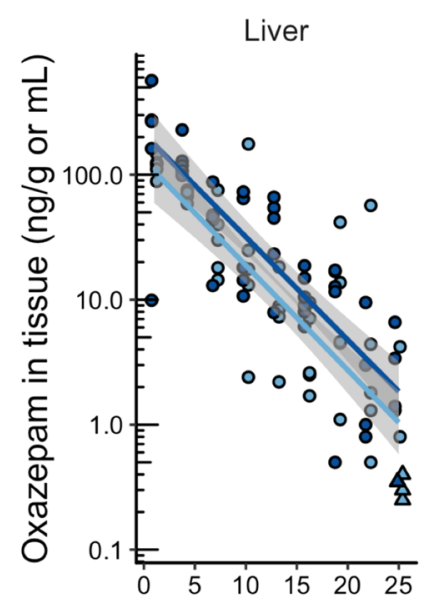

Vegetable shortening

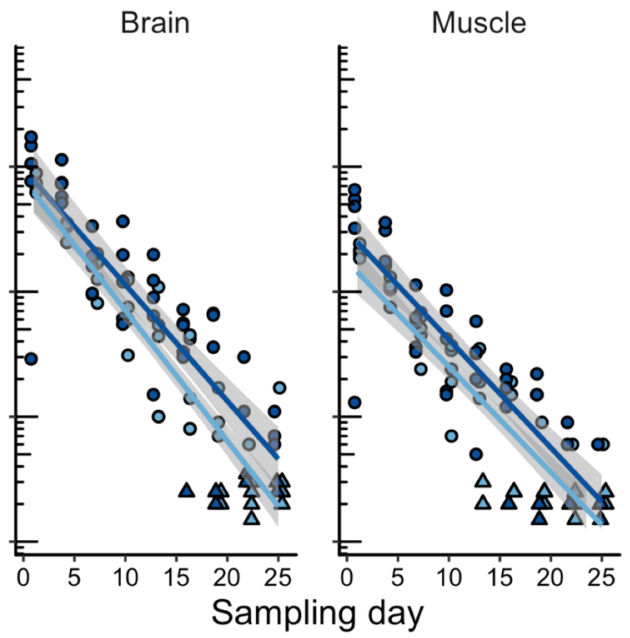

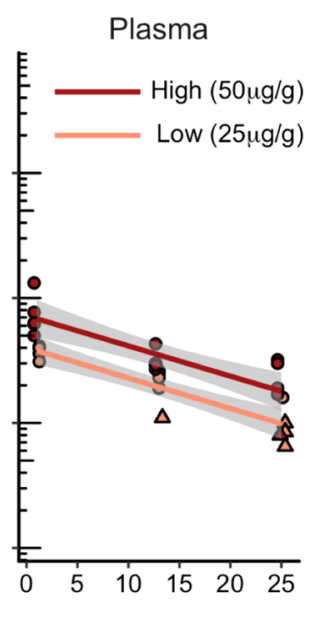

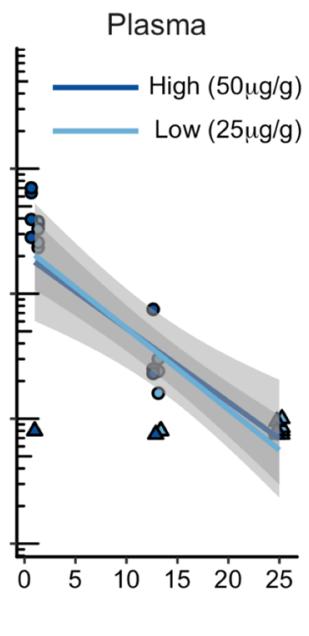

Figure 1. Tissue-specific uptake of oxazepam from the two implant carriers (A) coconut oil and (B) vegetable shortening plotted by exposure treatment on a log-scale. Solid lines show mean values and the shaded ribbons give the $95 \%$ confidence interval around the mean. Circles show values that were $>$ LOQ triangles show values that were $<$ LOQ. Any values that were $<$ LOQ were set to $1 / 2$ LOQ value (see Materials and Methods).

data file). We overlaid our data to determine at what water concentration a fish would have to be exposed to have the concentration of oxazepam in their tissues that we measured by using an implant. In all of the above analyses and in the following graphs, any samples that measured below the LOQ were set at half the LOQ value. ${ }^{37}$

\section{RESULTS AND DISCUSSION}

3.1. Tissue-Specific Uptake from the Implants. Oxazepam was not detected in any water samples and was < LOQ in all tissue and plasma samples from baseline and control fish as well as in the implants from control fish. For treated fish, oxazepam declined over the exposure period independent of carrier (Figure 1a,b; Table 1). This decline was faster for fish implanted with vegetable shortening (VS) than fish implanted with coconut oil (CO) and also depended on tissue (day*carrier*tissue interaction effect, Table 2). To breakdown this three-way interaction, we compared the slopes for each tissue within each carrier. Slopes did not differ among tissues for CO-implanted fish (all Tukey slope contrasts $p>$
0.3, Figure S1, Table S4), indicating that oxazepam was taken up from the implant consistently across time for all tissues. In contrast, the slopes for VS-implanted fish were all statistically different (all Tukey slope contrasts, $p<0.009$ ), except for liver and muscle ( $p=0.91$; Figure S1, Table S4). This indicates that uptake of oxazepam from VS implants was time- and tissuedependent. Specifically, oxazepam concentrations declined the fastest across time for brain tissue, the slowest across time for plasma, and intermediate for liver and muscle. Because the slopes were not different for CO-implanted fish, we compared oxazepam concentrations at an intermediate sampling point and found that oxazepam was highest in the liver $>$ brain $>$ plasma $=$ muscle (Figure 1a,b, Table 1 and Figure S2, Table S5). VS-implanted fish also tended to follow a similar pattern of tissue specific uptake (liver $>$ brain $>$ plasma $=$ muscle), but we did not statistically test this given the differences in slopes and caution that interpreting tissue-specific uptake requires also considering sampling time for this implant type.

Patterns of tissue-specific oxazepam uptake (liver and brain accumulating the most oxazepam) were similar to those from 
Table 1. Mean (s.d.) of Oxazepam Measured in Tissues, Plasma, and Implants ${ }^{a}$

\begin{tabular}{|c|c|c|c|c|c|c|}
\hline & \multicolumn{6}{|c|}{ Coconut Oil } \\
\hline & \multicolumn{3}{|c|}{ high, $50 \mu \mathrm{g} / \mathrm{g}$} & \multicolumn{3}{|c|}{ low, $25 \mu \mathrm{g} / \mathrm{g}$} \\
\hline & 1 day & 13 days & 25 days & 1 day & 13 days & 25 days \\
\hline \multirow[t]{2}{*}{ liver } & $39.7(37.6)$ & $41.20(47.4)$ & $44.8(69.1)$ & $33.9(23.0)$ & $7.1(1.8)$ & $8.6(4.6)$ \\
\hline & $5 / 5$ & $5 / 5$ & $5 / 5$ & $5 / 5$ & $5 / 5$ & $5 / 5$ \\
\hline \multirow[t]{2}{*}{ brain } & $15.9(5.8)$ & $8.8(2.2)$ & $4.3(2.0)$ & $9.0(2.8)$ & $3.7(1.1)$ & $2.7(1.3)$ \\
\hline & $5 / 5$ & $5 / 5$ & $5 / 5$ & $5 / 5$ & $5 / 5$ & $5 / 5$ \\
\hline \multirow[t]{2}{*}{ muscle } & $5.9(1.7)$ & $3.1(0.6)$ & $1.6(0.7)$ & $3.2(0.7)$ & $1.5(0.4)$ & $1.0(0.3)$ \\
\hline & $5 / 5$ & $5 / 5$ & $5 / 5$ & $5 / 5$ & $5 / 5$ & $5 / 5$ \\
\hline \multirow[t]{2}{*}{ plasma } & $7.7(3.2)$ & $3.2(0.6)$ & $2.1(1.0)$ & $3.8(0.4)$ & $2.1(0.6)$ & $1.0(0.4)$ \\
\hline & $5 / 5$ & $5 / 5$ & $4 / 5$ & $5 / 5$ & $4 / 5$ & $1 / 4$ \\
\hline \multirow[t]{5}{*}{ implant } & $13670(704)$ & $13430(912)$ & $10380(2388)$ & $9235(332)$ & $8434(1699)$ & $7292(513)$ \\
\hline & $3 / 3$ & $3 / 3$ & $3 / 3$ & $3 / 3$ & $3 / 3$ & $3 / 3$ \\
\hline & \multicolumn{6}{|c|}{ Vegetable Shortening } \\
\hline & \multicolumn{3}{|c|}{ high, $50 \mu \mathrm{g} / \mathrm{g}$} & \multicolumn{3}{|c|}{ low, $25 \mu \mathrm{g} / \mathrm{g}$} \\
\hline & 1 day & 13 days & 25 days & 1 day & 13 days & 25 days \\
\hline \multirow[t]{2}{*}{ liver } & $255.7(203.9)$ & $39.3(23.6)$ & $2.6(2.5)$ & $118.3(21.3)$ & $9.0(5.8)$ & $1.2(1.7)$ \\
\hline & $5 / 5$ & $5 / 5$ & $4 / 5$ & $5 / 5$ & $5 / 5$ & $2 / 5$ \\
\hline \multirow[t]{2}{*}{ brain } & $100.9(66.1)$ & $9.8(6.8)$ & $0.6(0.3)$ & $70.2(11.3)$ & $4.5(4.1)$ & $0.5(0.6)$ \\
\hline & $5 / 5$ & $5 / 5$ & $3 / 5$ & $5 / 5$ & $5 / 5$ & $1 / 5$ \\
\hline \multirow[t]{2}{*}{ muscle } & $40.1(24.9)$ & $3.0(2.0)$ & $0.3(0.2)$ & $21.1(2.4)$ & $1.5(1.4)$ & $0.3(0.2)$ \\
\hline & $5 / 5$ & $5 / 5$ & $1 / 5$ & $4 / 4$ & $3 / 5$ & $1 / 5$ \\
\hline \multirow[t]{2}{*}{ plasma } & $40.6(28.1)$ & $3.3(2.9)$ & NA & $31.2(6.3)$ & $1.7(1.0)$ & NA \\
\hline & $4 / 5$ & $3 / 4$ & $0 / 5$ & $5 / 5$ & $3 / 5$ & $0 / 5$ \\
\hline \multirow[t]{2}{*}{ implant } & $25123(36429)$ & $325(362)$ & $34(21)$ & $2467(784)$ & $139(160)$ & $21(9)$ \\
\hline & $3 / 3$ & $3 / 3$ & $3 / 3$ & $3 / 3$ & $3 / 3$ & $3 / 3$ \\
\hline
\end{tabular}

${ }^{a_{T}}$ Tissue and implants were measured in $\mathrm{ng} / \mathrm{g}$, plasma was measured in $\mathrm{ng} / \mathrm{mL}$. Below each mean is a ratio showing the number of samples in which oxazepam was detected above the limit of quantification (LOQ) over the total number of samples (sample size). For the means, any samples $<$ LOQ were set to $1 / 2$ the LOQ value (see Materials and Methods).

Table 2. Results and Model Output from a Linear Mixed Effects Model Testing for the Effects of Sampling Day, Carrier Type, Treatment, and Tissue Type on Oxazepam Concentration

\begin{tabular}{lccccc} 
& sum sq & mean sq & df & $F$ & $p$ \\
day & 93.19 & 93.19 & 1175 & 393.18 & $<0.0001$ \\
carrier & 20.59 & 20.59 & 1180 & 86.86 & $<0.0001$ \\
treatment & $\mathbf{9 . 1 1}$ & $\mathbf{9 . 1 1}$ & $\mathbf{1 1 7 3}$ & $\mathbf{3 8 . 4 2}$ & $<0.0001$ \\
tissue & 104.68 & 34.89 & 3408 & 147.21 & $<0.0001$ \\
day*carrier & 31368 & 31.36 & 1175 & 132.30 & $<0.0001$ \\
day*tissue & 6.17 & 2.06 & 3407 & 8.68 & $<0.0001$ \\
carrier*tissue & 0.77 & 0.26 & 3407 & 1.08 & 0.36 \\
day*carrier*tissue & $\mathbf{5 . 6 1}$ & $\mathbf{1 . 8 7}$ & $\mathbf{3 4 0 7}$ & $\mathbf{7 . 8 8}$ & $<\mathbf{0 . 0 0 0 1}$ \\
\hline
\end{tabular}

previous laboratory studies that used waterborne oxazepam exposures, ${ }^{23,28}$ except for plasma, because the relative uptake in plasma has varied across studies. More generally, our findings also align with previous work showing that psychoactive pharmaceuticals in general tend to bioconcentrate most in the brain and liver. ${ }^{38-42}$ Many interacting variables will determine tissue-specific uptake (e.g., species-specific factors, environmental or exposure characteristics, physicochemical CEC properties), ${ }^{42,43}$ but the implants in our study successfully distributed oxazepam among tissues similarly to waterborne exposures.

3.2. Dose Delivery from the Implants. For both implant types and all tissues, fish exposed to the high dose had more oxazepam in their tissues than the low dose (effect of treatment, Table 2; Figure 1a,b). Oxazepam treatment did not affect the implant-BCF (LMM, effect of treatment, $F_{(1173)}$ $=2.03, p=0.16$ ) or interact with any other factors (e.g., tissue, sampling time, carrier; all interaction effects $p>0.1$ ), indicating that uptake from the implants was proportional to the treatment received for both carriers. However, the concentration of oxazepam measured directly in the implants was lower than the nominal concentrations for both treatments when sampled after $24 \mathrm{~h}$ (Table 1). Clearly, some compound had migrated to the surrounding body tissues, but it is possible that oxazepam does not dissolve well in fat-based implants or that the oxazepam is unevenly distributed in the implants or a combination of both. High RSDs in the recovery experiments supports the explanation that the oxazepam is unevenly distributed. The decline of oxazepam in the implants over time closely reflected the decline of oxazepam in fish tissues and plasma over time, where CO-implants and implanted fish showed more stable oxazepam levels, while oxazepam in VSimplants and implanted fish declined quickly across the exposure period (Table 1, Figure S3). Previously, Birnie- 
A
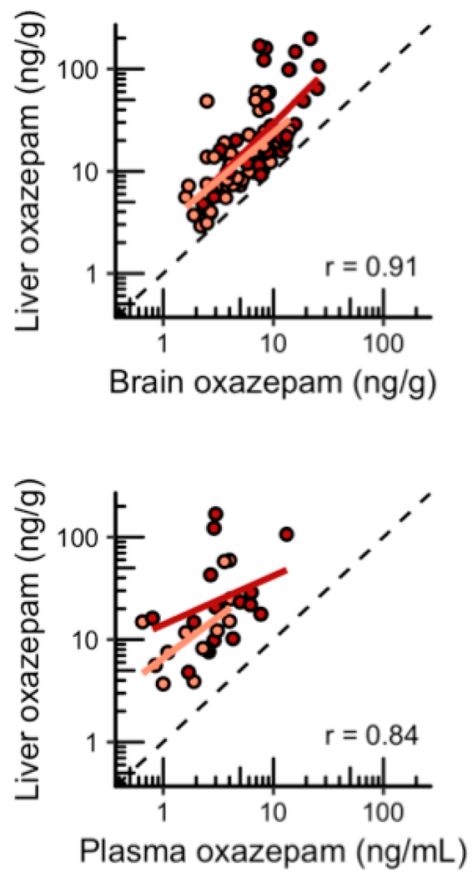

B
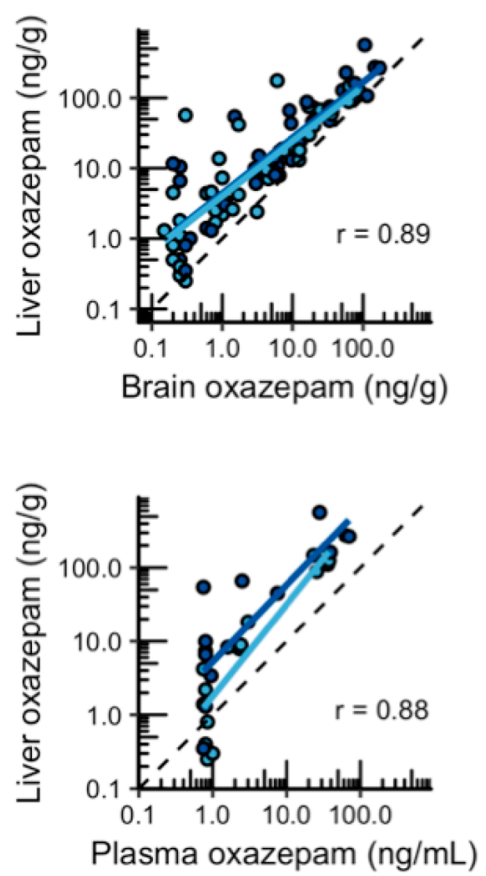

Coconut oil
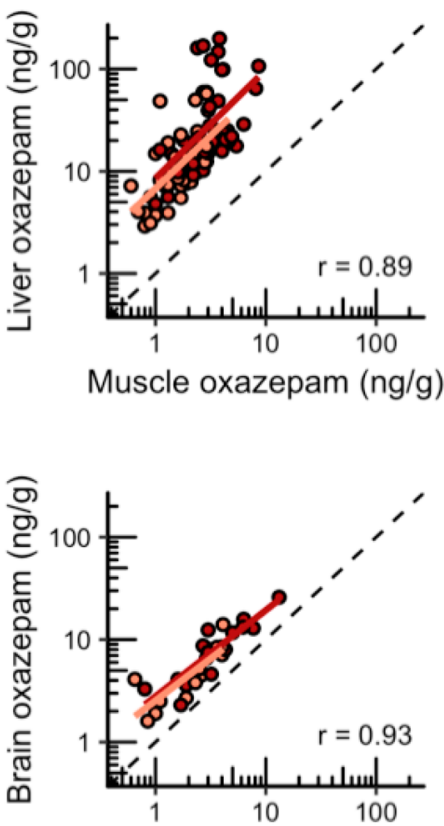

Plasma oxazepam $(\mathrm{ng} / \mathrm{mL})$

\section{Vegetable shortening}
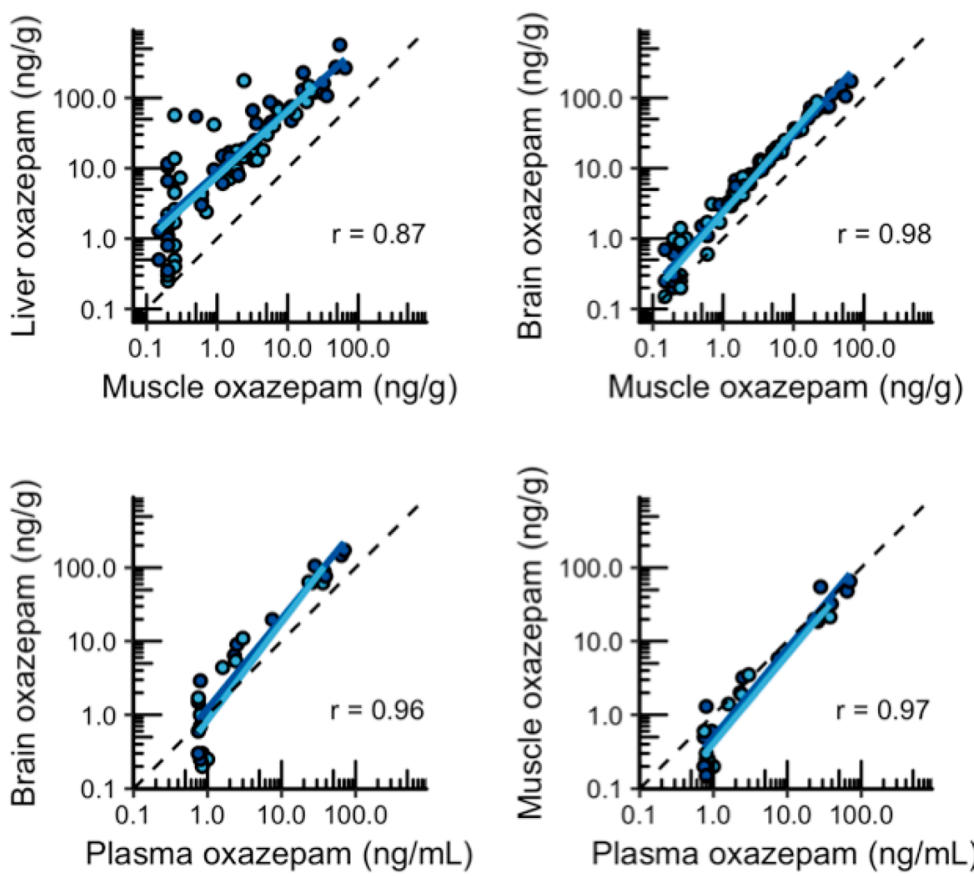
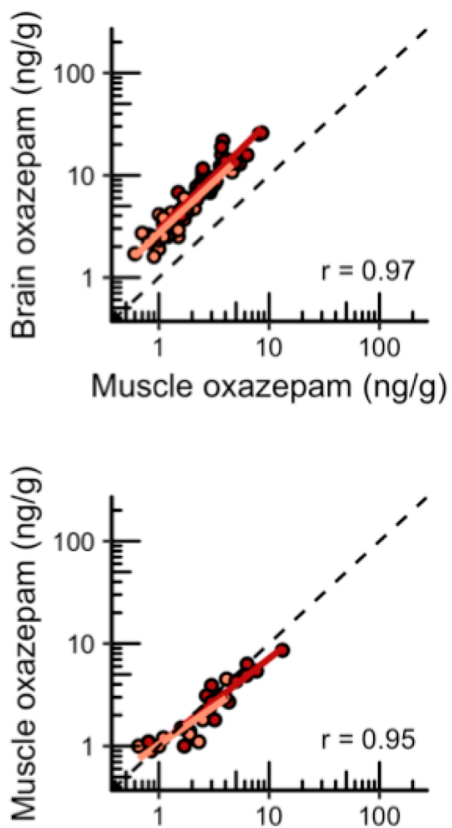

Plasma oxazepam $(\mathrm{ng} / \mathrm{mL})$

Figure 2. Comparative uptake of oxazepam in tissues and plasma for fish implanted with (A) coconut oil or (B) vegetable shortening plotted by treatment on a log-scale. Dark red and dark blue indicate the high-exposure treatment; light red and light blue indicate the low-exposure treatment for each carrier, respectively. Pearson $R$ correlation coefficients are plotted on all graphs. All correlations were statistically significant $(p<0.001)$.

Gauvin et al. $^{30}$ noted that VS-implants released a higher dose of cortisol to fish tissues than cocoa butter (not tested here) and attributed this, in part, to the soft texture of VS at low temperatures. In this study, VS and CO implants were both pliable at low temperatures when removed during dissection $\left(\sim 5-10{ }^{\circ} \mathrm{C}\right.$ ), but $\mathrm{CO}$ implants were firmer (McCallum, E., personal observations). Differences in oxazepam release from the two implant types may be driven by differences in fatty acid composition. VS has a higher proportion of unsaturated fat to saturated fat when compared to CO (2.42 versus 0.0086, respectively). The rheological properties that govern the deformation and flow of matter in response to an applied stress will also differ between the implants. Further studies are needed in order to correlate the properties of the implants with the release of oxazepam in fish (e.g., exploring compound release from fat carriers with different compositions and 


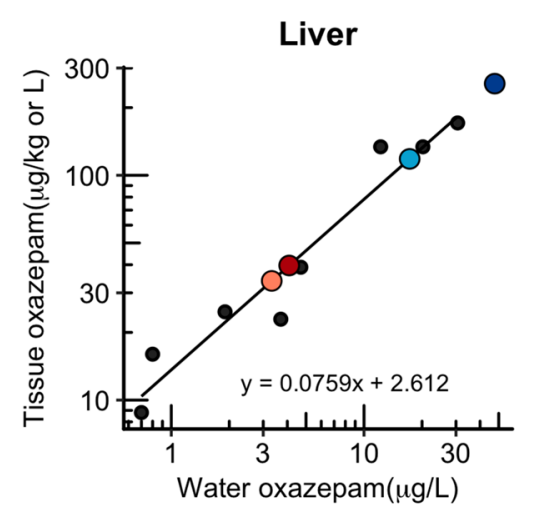

Muscle

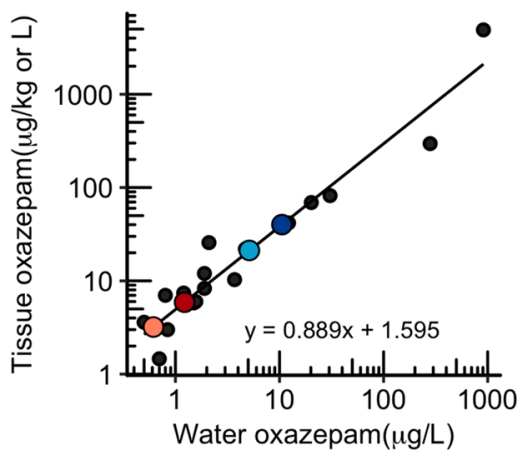

Brain

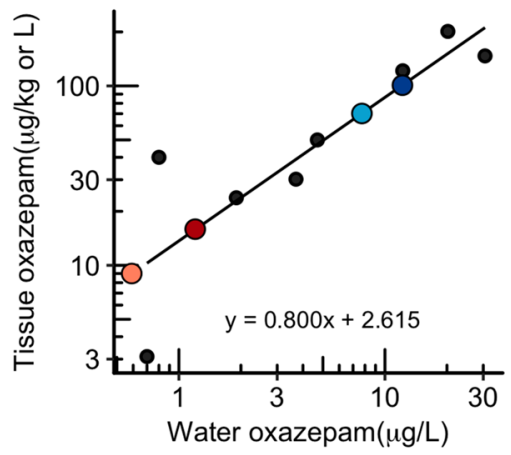

Plasma

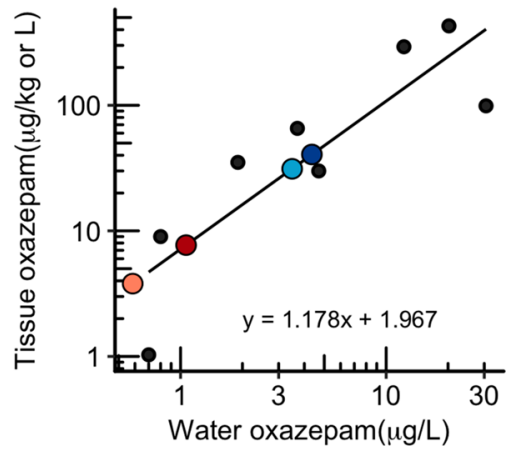

Figure 3. Scatter plot estimating the waterborne concentration of oxazepam needed to cause the level of oxazepam in tissues found in our study. Black circles and regression line show tissue concentrations and waterborne exposure concentrations from previous oxazepam exposure studies (see the supplementary data file for full listing). Colored points show the tissue concentrations after $24 \mathrm{~h}$ of implant exposure from each experimental group in our study (light red CO low; dark red CO high; light blue VS low; dark blue VS high). See Figure S4ab for days 13 and 25.

physicochemical characteristics, measuring diffusion from implants across synthetic membranes, imaging to identify structural breakdown of the implant).

3.3. Implant Exposure Variability. We measured oxazepam variability from each tissue and implant type to verify exposure consistency. Interindividual differences were consistent across tissue types with respect to the accumulation of oxazepam (i.e., individuals that had high concentrations in their livers also had high concentrations in their other tissues; correlation coefficients, Figure 2). Overall, interindividual variation in oxazepam was higher for VS-implanted fish than CO-implanted fish (see standard deviations, Table 1). This pattern of oxazepam variation was also present in the implants, where VS implants were more variable than $\mathrm{CO}$ implants (Table 1; Figure S3). Oxazepam may be more heterogeneously distributed in VS implants than CO implants, even though both implant types were prepared following the same methodology. The similar pattern of oxazepam concentrations in the tissues and implants indicates that oxazepam likely diffuses from the implant to the surrounding tissues creating an equilibrium that declines as oxazepam is cleared from tissues (via glucuronidation ${ }^{44}$ ) and replenished from the implant. Across tissue types, liver tissue showed the most variation in oxazepam concentrations for both implant types (Figure 1, Figure 2). This may be due to variable water content that is typical in fish livers. Additionally, the liver is positioned in the body cavity where it may come in direct contact with the implant, whereas the other tissues are in separate body compartments.

3.4. Evaluation and Application of This Method. Our results indicate that coconut oil implant was the superior because it delivered a stable and consistent exposure over time that would be well-suited for large-scale and/or long-term studies in the wild. Using data from previous waterborne exposure studies, we also determined what concentration of oxazepam in the water that would cause the tissue concentrations measured in our study (Figure 3; supplementary data file). This showed that $\mathrm{CO}$ implants were also superior at creating an oxazepam exposure that would be similar to an environmentally relevant waterborne exposure in most tissues (i.e., exposure to $<1 \mu \mathrm{g} / \mathrm{L}$, reported in surface waters and treated wastewater discharges $\left.{ }^{17,21}\right)$. For example, oxazepam measured in the muscle from fish with $\mathrm{CO}$ implants was similar to European perch $\left(\sim 4 \mathrm{ng} / \mathrm{g}^{21}\right)$ collected downstream from a wastewater outfall. In contrast, VS implants were variable and gave a much higher initial oxazepam exposure (Figure 3 ) that rapidly decreased. It is worthwhile to note that even though oxazepam concentrations in tissues and distribution among tissues were similar to waterborne exposures (for CO-implants), uptake mechanisms are still likely to differ between the two exposure methods.

Slow-release implants have largely been used in laboratory environments to manipulate steroid hormone levels in aquatic organisms. To our knowledge, this study is the first to provide comprehensive data on the release and tissue-specific uptake for a CEC from implants in aquatic organisms. This study is also the first to quantify CECs directly in an implant itself, while previous work has relied largely on downstream biological effects. Based on our results, we are confident that this method is a useful tool for field ecotoxicology and will more than likely play an important part in increasing fieldbased ecotoxicology studies. Field experiments are crucial for 
informing environmental risk assessment, policy, and conservation, but the financial cost and risk they pose for collaterally impacting wildlife means that these studies are rarely conducted. Implants would greatly reduce large-scale environmental contamination caused by whole environment exposures, but we must also acknowledge that implanted fish will excrete a small amount of oxazepam back to the water column, and predator animals (e.g., predatory water birds) could still be exposed if they fully consumed implanted fish in the field. Using implants would still address many logistical and financial issues associated with large-scale exposures, and they will open up new avenues for "scaling up" research in ecotoxicology. For instance, implants could be combined with recent advances in animal tracking technology $y^{3,45}$ (e.g., acoustic telemetry), allowing researchers to quantify the finescale behavioral and physiological effects of CECs in real-time in the natural environment. ${ }^{3}$ In conclusion, slow-release implants (coconut oil, in particular) are an effective and practical method for manipulating CEC exposures in aquatic wildlife, and as such they are an important tool for field ecotoxicology. The next steps will be to expand this methodology to encompass a range of CEC compounds and more species and to better understand temperature effects on CEC release.

\section{ASSOCIATED CONTENT}

\section{(S) Supporting Information}

The Supporting Information is available free of charge on the ACS Publications website at DOI: 10.1021/acs.est.9b01975.

Additional information on data analyses and results of previous oxazepam exposure studies (XLSX)

Plot showing tissue by sampling day interaction effect; Tukey post-hoc contrast plots generated by emmeans; concentrations of oxazepam measured directly in coconut oil or vegetable shortening implants; scatter plot estimating the waterborne concentration of oxazepam needed to cause the level of oxazepam in tissues; mean standard body length, sample size, and sex of fish used in this experiment; HESI ion source and MS/MS settings of the instrument; LOQs and recoveries of oxazepam in different matrixes measured within this study; results of Tukey-post hoc comparisons among the slopes for fish implanted with coconut oil or vegetable shortening; and results of Tukey post-hoc comparisons among group means for fish implanted with coconut oil (PDF)

\section{AUTHOR INFORMATION}

\section{Corresponding Author}

*E-mail: erin.mccallum@slu.se.

\section{ORCID}

Erin S. McCallum: 0000-0001-5426-9652

\section{Notes}

The authors declare no competing financial interest.

\section{ACKNOWLEDGMENTS}

We would like to thank R. Linderot for assistance with the fish collection and Tova Brodin for assistance with graphics. This project was supported by a FORMAS grant to T. Brodin (Grant 2013-734). E. S. McCallum is supported by the
Wenner-Gren Foundation, and D. Cerveny is supported by the Kempe Foundation.

\section{ABBREVIATIONS}

CEC contaminants of emerging concern

$\mathrm{CO}$ coconut oil

IP intraperitoneal

LMM linear mixed effects model

LOQ limit of quantification

VS vegetable shortening

\section{REFERENCES}

(1) Saaristo, M.; Brodin, T.; Balshine, S.; Bertram, M. G.; Brooks, B. W.; Ehlman, S. M.; McCallum, E. S.; Sih, A.; Sundin, J.; Wong, B. B. M.; Arnold, K. E. Direct and Indirect Effects of Chemical Contaminants on the Behaviour, Ecology and Evolution of Wildlife. Proc. R. Soc. London, Ser. B 2018, 285, 20181297.

(2) Windsor, F. M.; Ormerod, S. J.; Tyler, C. R. Endocrine Disruption in Aquatic Systems: Up-Scaling Research to Address Ecological Consequences. Biol. Rev. 2018, 93 (1), 626-641.

(3) Hellström, G.; Klaminder, J.; Jonsson, M.; Fick, J.; Brodin, T. Upscaling Behavioural Studies to the Field Using Acoustic Telemetry. Aquat. Toxicol. 2016, 170, 384-389.

(4) Nilsen, E.; Smalling, K. L.; Ahrens, L.; Gros, M.; Miglioranza, K. S. B.; Pico, Y.; Schoenfuss, H. L. Grand Challenges in Assessing the Adverse Effects of Contaminants of Emerging Concern on Aquatic Food Webs. Environ. Toxicol. Chem. 2019, 38, 46-60.

(5) Pal, A.; Gin, K. Y. H.; Lin, A. Y. C.; Reinhard, M. Impacts of Emerging Organic Contaminants on Freshwater Resources: Review of Recent Occurrences, Sources, Fate and Effects. Sci. Total Environ. 2010, 408 (24), 6062-6069.

(6) Loos, R.; Carvalho, R.; António, D. C.; Comero, S.; Locoro, G.; Tavazzi, S.; Paracchini, B.; Ghiani, M.; Lettieri, T.; Blaha, L.; Jarosova, B. EU-Wide Monitoring Survey on Emerging Polar Organic Contaminants in Wastewater Treatment Plant Effluents. Water Res. 2013, 47 (17), 6475-6487.

(7) Forbes, V. E.; Calow, P.; Sibly, R. M. The Extrapolation Problem and How Population Modeling Can Help. Environ. Toxicol. Chem. 2008, 27 (10), 1987-1994.

(8) Hamilton, P. B.; Cowx, I. G.; Oleksiak, M. F.; Griffiths, A. M.; Grahn, M.; Stevens, J. R.; Carvalho, G. R.; Nicol, E.; Tyler, C. R. Population-Level Consequences for Wild Fish Exposed to Sublethal Concentrations of Chemicals - a Critical Review. Fish Fish. 2016, 17, $545-566$.

(9) Kidd, K. A.; Blanchfield, P. J.; Mills, K. H.; Palace, V. P.; Evans, R. E.; Lazorchak, J. M.; Flick, R. W. Collapse of a Fish Population after Exposure to a Synthetic Estrogen. Proc. Natl. Acad. Sci. U. S. A. 2007, 104 (21), 8897-8901.

(10) Kidd, K. A.; Paterson, M. J.; Rennie, M. D.; Podemski, C. L.; Findlay, D. L.; Blanchfield, P. J.; Liber, K. Direct and Indirect Responses of a Freshwater Food Web to a Potent Synthetic Oestrogen. Philos. Trans. R. Soc., B 2014, 369, 20130578.

(11) Sopinka, N. M.; Patterson, L. D.; Redfern, J. C.; Pleizier, N. K.; Belanger, C. B.; Midwood, J. D.; Crossin, G. T.; Cooke, S. J. Manipulating Glucocorticoids in Wild Animals: Basic and Applied Perspectives. Conserv. Physiol. 2015, 3 (1), cov031.

(12) Mylonas, C. C.; Zohar, Y. Use of GnRHa-Delivery Systems for the Control of Reproduction in Fish. Rev. Fish Biol. Fish. 2000, 10, 463-491.

(13) Zaroogian, G. E.; Gutjahr-Gobell, R. E.; Horowitz, D. B.; Jayaraman, S.; Cantwell, M.; Chichester, C. O.; Mills, L. J. An Injectable, Slow-Release Implantation Method for Exposing Fish to Chemicals over a Period of Weeks. N. Am. J. Aquac. 2012, 74 (4), 512-521.

(14) McDonald, M. D.; Gonzalez, A.; Sloman, K. a. Higher Levels of Aggression Are Observed in Socially Dominant Toadfish Treated with the Selective Serotonin Reuptake Inhibitor, Fluoxetine. Comp. Biochem. Physiol., Part C: Toxicol. Pharmacol. 2011, 153 (1), 107-112. 
(15) Sonnenberg, C. M.; Bierman, E. J. M.; Deeg, D. J. H.; Comijs, H. C.; Van Tilburg, W.; Beekman, A. T. F. Ten-Year Trends in Benzodiazepine Use in the Dutch Population. Soc. Psychiatry Psychiatr. Epidemiol. 2012, 47 (2), 293-301.

(16) Olfson, M.; King, M.; Schoenbaum, M. Benzodiazepine Use in the United States. JAMA Psychiatry 2015, 72 (2), 136-142.

(17) Fick, J.; Brodin, T.; Heynen, M.; Klaminder, J.; Jonsson, M.; Grabicova, K.; Randak, T.; Grabic, R.; Kodes, V.; Slobodnik, J.; Sweetman, A. Screening of Benzodiazepines in Thirty European Rivers. Chemosphere 2017, 176, 324-332.

(18) Klaminder, J.; Brodin, T.; Sundelin, A.; Anderson, N. J.; Fahlman, J.; Jonsson, M.; Fick, J. Long-Term Persistence of an Anxiolytic Drug (Oxazepam) in a Large Freshwater Lake. Environ. Sci. Technol. 2015, 49 (17), 10406-10412.

(19) Cunha, D. L.; de Araujo, F. G.; Marques, M. Psychoactive Drugs: Occurrence in Aquatic Environment, Analytical Methods, and Ecotoxicity-a Review. Environ. Sci. Pollut. Res. 2017, 24 (31), 24076-24091.

(20) Brodin, T.; Nordling, J.; Lagesson, A.; Klaminder, J.; Hellström, G.; Christensen, B.; Fick, J. Environmental Relevant Levels of a Benzodiazepine (Oxazepam) Alters Important Behavioral Traits in a Common Planktivorous Fish, (Rutilus Rutilus). J. Toxicol. Environ. Health, Part A 2017, 80, 963-970.

(21) Brodin, T.; Fick, J.; Jonsson, M.; Klaminder, J. Dilute Concentrations of a Psychiatric Drug Alter Behavior of Fish from Natural Populations. Science (Washington, DC, U. S.) 2013, 339 (6121), 814-815.

(22) Hellström, G.; Klaminder, J.; Finn, F.; Persson, L.; Alanärä, A.; Jonsson, M.; Fick, J.; Brodin, T. GABAergic Anxiolytic Drug in Water Increases Migration Behaviour in Salmon. Nat. Commun. 2016, 7, 13460 .

(23) Huerta, B.; Margiotta-Casaluci, L.; Rodriguez-Mozaz, S.; Scholze, M.; Winter, M. J.; Barcelo, D.; Sumpter, J. P. Anti-Anxiety Drugs and Fish Behavior: Establishing the Link between Internal Concentrations of Oxazepam and Behavioral Effects. Environ. Toxicol. Chem. 2016, 35 (11), 2782-2790.

(24) de Abreu, M. S.; Koakoski, G.; Ferreira, D.; Acosta Oliveira, T.; Santos Da Rosa, J. G.; Gusso, D.; Varrone Giacomini, A. C.; Piato, A. L.; Barcellos, L. J. G. Diazepam and Fluoxetine Decrease the Stress Response in Zebrafish. PLoS One 2014, 9 (7), e103232.

(25) Sundin, J.; Jutfelt, F.; Thorlacius, M.; Fick, J.; Brodin, T. Behavioural Alterations Induced by the Anxiolytic Pollutant Oxazepam Are Reversible after Depuration in a Freshwater Fish. Sci. Total Environ. 2019, 665, 390-399.

(26) McCallum, E. S.; Sundelin, A.; Fick, J.; Alanärä, A.; Klaminder, J.; Hellström, G.; Brodin, T. Investigating Tissue Bioconcentration and the Behavioural Effects of Two Pharmaceutical Pollutants on Sea Trout (Salmo Trutta) in the Laboratory and Field. Aquat. Toxicol. 2019, 207, 170-178.

(27) Cunha, D. L.; Mendes, M. P.; Marques, M. Environmental Risk Assessment of Psychoactive Drugs in the Aquatic Environment. Environ. Sci. Pollut. Res. 2019, 26, 78.

(28) Heynen, M.; Brodin, T.; Klaminder, J.; Jonsson, M.; Fick, J. Tissue-Specific Uptake of the Benzodiazepine Oxazepam in Adult Eurasian Perch (Perca Fluviatilis). Environ. Chem. 2016, 13 (5), 849853.

(29) Andersson, P. L.; Fick, J.; Rännar, S. A Multivariate Chemical Similarity Approach to Search for Drugs of Potential Environmental Concern. J. Chem. Inf. Model. 2011, 51 (8), 1788-1794.

(30) Birnie-Gauvin, K.; Peiman, K. S.; Larsen, M. H.; Aarestrup, K.; Gilmour, K. M.; Cooke, S. J. Comparison of Vegetable Shortening and Cocoa Butter as Vehicles for Cortisol Manipulation in Salmo Trutta. J. Fish Biol. 2018, 92, 229-236.

(31) Gamperl, A. K.; Vijayan, M. M.; Boutilier, R. G. Experimental Control of Stress Hormone Levels in Fishes: Techniques and Applications. Rev. Fish Biol. Fish. 1994, 4 (2), 215-255.

(32) McConnachie, S. H.; Cook, K. V.; Patterson, D. A.; Gilmour, K. M.; Hinch, S. G.; Farrell, A. P.; Cooke, S. J. Consequences of Acute Stress and Cortisol Manipulation on the Physiology, Behavior, and
Reproductive Outcome of Female Pacific Salmon on Spawning Grounds. Horm. Behav. 2012, 62 (1), 67-76.

(33) Grabic, R.; Fick, J.; Lindberg, R. H.; Fedorova, G.; Tysklind, M. Multi-Residue Method for Trace Level Determination of Pharmaceuticals in Environmental Samples Using Liquid Chromatography Coupled to Triple Quadrupole Mass Spectrometry. Talanta 2012, 100, 183-195.

(34) R Core Team. R: A Language and Environment for Statistical Computing; R Foundation for Statistical Computing: Vienna, Austria, 2018.

(35) Bates, D.; Maechler, M.; Bolker, B.; Walker, S. Fitting Linear Mixed-Effects Models Using lme4. J. Stat. Softw. 2015, 67 (1), 1-48.

(36) Lenth, R.. Emmeans: Estimated Marginal Means, aka LeastSquares Means, $R$ Package, version 1.3.0; 2018.

(37) Duval, V.; Karlsson, M. O. Impact of Omission or Replacement of Data below the Limit of Quantification on Parameter Estimates in a Two-Compartment Model. Pharm. Res. 2002, 19 (12), 1835-1840.

(38) Grabicova, K.; Grabic, R.; Fedorova, G.; Fick, J.; Cerveny, D.; Kolarova, J.; Turek, J.; Zlabek, V.; Randak, T. Bioaccumulation of Psychoactive Pharmaceuticals in Fish in an Effluent Dominated Stream. Water Res. 2017, 124, 654-662.

(39) Grabicova, K.; Lindberg, R. H.; Östman, M.; Grabic, R.; Randak, T.; Joakim Larsson, D. G.; Fick, J. Tissue-Specific Bioconcentration of Antidepressants in Fish Exposed to Effluent from a Municipal Sewage Treatment Plant. Sci. Total Environ. 2014, 488-489 (1), 46-50.

(40) Brooks, B. W.; Chambliss, C. K.; Stanley, J. K.; Ramirez, A.; Banks, K. E.; Johnson, R. D.; Lewis, R. J. Determination of Select Antidepressants in Fish from an Effluent-Dominated Stream. Environ. Toxicol. Chem. 2005, 24 (2), 464-469.

(41) Arnnok, P.; Singh, R. R.; Burakham, R.; Pérez-Fuentetaja, A.; Aga, D. S. Selective Uptake and Bioaccumulation of Antidepressants in Fish from Effluent-Impacted Niagara River. Environ. Sci. Technol. 2017, 51 (18), 10652-10662.

(42) Tanoue, R.; Nomiyama, K.; Nakamura, H.; Kim, J. W.; Isobe, T.; Shinohara, R.; Kunisue, T.; Tanabe, S. Uptake and Tissue Distribution of Pharmaceuticals and Personal Care Products in Wild Fish from Treated-Wastewater-Impacted Streams. Environ. Sci. Technol. 2015, 49 (19), 11649-11658.

(43) Zenker, A.; Cicero, M. R.; Prestinaci, F.; Bottoni, P.; Carere, M. Bioaccumulation and Biomagnification Potential of Pharmaceuticals with a Focus to the Aquatic Environment. J. Environ. Manage. 2014, $133,378-387$.

(44) Greenblatt, D. J. Clinical Pharmacokinetics of Oxazepam and Lorazepam. Clin. Pharmacokinet. 1981, 6, 89-105.

(45) Hussey, N. E.; Kessel, S. T.; Aarestrup, K.; Cooke, S. J.; Cowley, P. D.; Fisk, A. T.; Harcourt, R. G.; Holland, K. N.; Iverson, S. J.; Kocik, J. F.; Flemming, J. E. M. Aquatic Animal Telemetry: A Panoramic Window into the Underwater World. Science (Washington, DC, U. S.) 2015, 348, 1255642. 